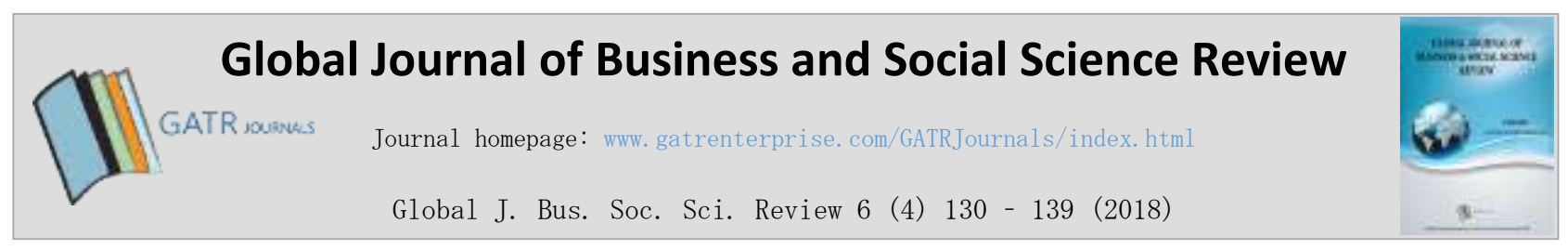

\title{
Does The Stock of Indonesian Provider Tower Industry Have a Fair Value?
}

\author{
Saptono, ${ }^{1 *}$ Farida Titik Kristanti ${ }^{2}$ \\ ${ }^{1,2}$ Graduate Study Program of Management, Faculty of Economics and Business, Telkom University, Gegerkalong \\ Street, 40153, Bandung, Indonesia
}

\begin{abstract}
Objective - The objective of this study is to evaluate the stock intrinsic value of companies listed on the Indonesian Stock Exchange. The evaluation is carried out by using a DCF method of Free Cash Flow to Firm (FCFF) approach, and a relative method of Price to Earnings Ratio (PER) and Price to Book Value (PBV) approaches. Each approach uses three scenarios of optimism, moderation and pessimism.

Methodology/Technique - The historical data of the companies between 2014 and 2017 was used to predict their performance in the period between 2018 and 2021.

Findings - The results of this study indicate that by comparing the stock prices to their intrinsic value of the stock valuation of the DCF-FCFF, the stock market prices as of 1 January 2018 according to the optimistic scenario show that TBIG and SUPR were undervalued, while TOWR and IBST were overvalued. In the moderate scenario, TBIG and SUPR were undervalued, while TOWR and IBST were overvalued.

Novelty - Meanwhile, TBIG, TOWR and IBST were overvalued and only SUPR was undervalued in the pessimistic scenario. Relative valuation using a PER approach in all scenarios indicates that TBIG, TOWR and IBST were overvalued and SUPR was undervalued. Finally, through a PBV approach, the relative valuation of TOWR, SUPR and IBST were overvalued and TBIG was undervalued in all scenarios.
\end{abstract}

Type of Paper: Empirical.

Keywords: Free Cash Flow to Firm; Relative Valuation; Tower Provider Industry; Intrinsic Value; Valuation. JEL Classification: G14, G15, G19.

\section{Introduction}

Nowadays, the development of the digital era requires support for telecommunication infrastructure to be considerably promising. Telecommunication infrastructure development needs are usually fulfilled by tower providers. This is indicated by the number of tower provider stocks listed on the Indonesian Stock Exchange.

\footnotetext{
* Paper Info: Revised: August 12, 2018

Accepted: December 9, 2018

* Corresponding author: Saptono

E-mail:saptono31@yahoo.com

Affiliation: Faculty of economics and business, Telkom University, Indonesia
} 
The characteristics of the tower provider industry are indicated by a stable and predictable cash flow evidenced by the amount of annual/monthly rent that is usually calculated in a predetermined contract. The contract lease agreements generally consist of fixed rental rates and adjusted maintenance costs each year with inflation. This industry also has a characteristic of repeating income streams. The cost of transferring a Base Transceiver System (BTS) is so expensive that at the end of the lease contract, it is likely that the tenant will extend the lease. Tower providers can grow by developing new towers (organic expansion) as well as acquiring new towers owned by other providers (inorganic expansion), which may affect stock prices. The development of the tower provider industry stocks is dynamic, as shown in Figure 1.1. In the period of 20142017, IBST stock price experienced a $28.19 \%$ increase, while the stock prices of TBIG, TOWR and SUPR declined as much as $-9.79 \%,-3.06 \%$ and $-0.92 \%$ respectively.

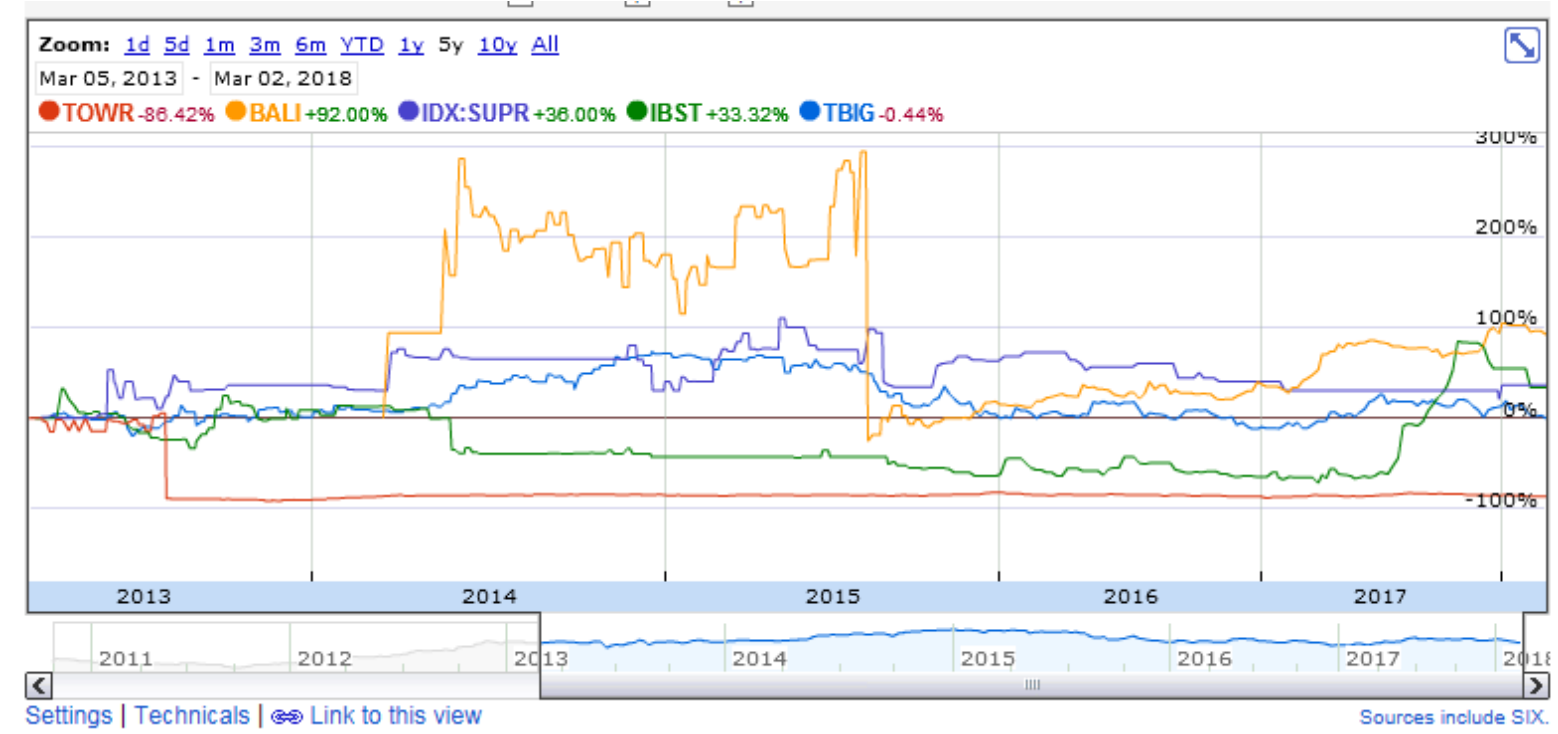

Figure 1.1 The Chart of Stock Price Growth of Tower Provider Industry in the period of 2014-2017 Source: Google Finance

Damodaran (2012) defines the intrinsic value of a stock as the current value of the cash flows that will be obtained over the life of the company. Stock valuation is the process of determining the reasonable price for a stock. Furthermore, in general, Damodaran (2012) classifies 3 methods used in valuation, namely (i) Discounted Cash Flow valuation, (ii) Contingent Claim valuation, and (iii) Relative valuation. The Discounted Cash Flow (DCF) valuation states that the value of an asset is the present value of cash flow expectations that will be generated in the future at a certain discount rate. It consists of three types of valuation approaches according to their respective needs. They are: Dividend Discounted Model (DDM), Free Cash Flow to Equity (FCFE), and Free Cash Flow to the Firm (FCFF). The FCFF shows the amount of cash flows to all stakeholders, including stockholders, bondholders and preferred stock holders (Damodaran, 2012). The estimates of the companies' value is derived from the present value of cash flows by assuming that all equity financing added by the net present value of the tax was made by using debt. Meanwhile, the Contingent Claim Valuation is a valuation model used to measure the value of an asset sharing the characteristics of an option. Originally, the model was used to assess traded options, and recently it has been used for a more traditional assessment. The definition of the model is that the discounted cash flow model tends to understate the value of an assets that provides rewards depending on the occurrence of an event. Another method used in stock valuation is a relative valuation method. In this method, assets are assessed based on the asset price in the market.

The FCFF method was chosen for this study due to its ability to capture the potential of future growth. At the same time, PER method was chosen because it can facilitate or assist the researchers to 
determine analyses. Although the Price Earnings Ratio is a relatively simple analysis, as acknowledged, it assists stock analysts to focus on important variables. The PBV method was selected because it allows investors to compare the book value of a stock with its market value. The PBV ratio can provide information about the frequency of the market value of a stock that is based on its book value.

In addition, Gumanti (2011) explains that every investor has different provisions in stock valuations that cause changes to stock prices. These differences refer to several conditions of optimism, moderation and pessimism. Optimism is a condition in which investors can sell stocks with the highest potential prices. Moderation is a condition in which investors sell stocks in accordance with the wishes of other investors (buyers). Meanwhile, pessimism is a condition in which investors can buy stocks at the lowest price.

Many researchers conduct researches on the valuation on stock prices. Churamati and Suraj (2014) compare various models for bank stock price valuation of 14 banks belonging to the BSE bankex of the Indian Stock Exchange. The research resulted in the highest value of Ohlson and PBV models compared to CAPM, DDM, PER or Excess Return. Ivanovski, Ivanovska and Narasanov (2015) examine the effectiveness of the DDM model for the valuation of stocks on the Macedonian Stock Exchange (MSE). That study shows that the DDM Model is very useful when used together with the relative model. Santos (2017) studied the valuation of Adidas Group stocks using DCF-APV, DDM, and EV / EBITDA relative models. The results of that research reveal that the current stock price (market price) was overvalued against the intrinsic value of the stock. Meanwhile, Benaji (2011) observes the valuation of the intrinsic value of Perum Pegadaian stocks using the FCFE method. That study concludes that the intrinsic value of the Pegadaian stock ranges from IDR $1,716.40$ to IDR 3,859.35 per stock.

Kasim (2011) examines the valuation of the stock intrinsic value of PT Garuda Indonesia Tbk using the Present Value to EBITDAR cash flow and Hidden Value method, concluding that the market price of PT Garuda Indonesia stocks was undervalued compared to its intrinsic value. The research of Simorangkir (2011) on the valuation of stock intrinsic value of PT BNI Tbk using a Discounted Earnings Approach (DEA) and PBV methods resulted in an undervalued stock market price when compared to its intrinsic value. Hutapea, Putri and Sihombing (2012) examine the intrinsic price valuation of PT Adaro Energi Tbk stocks using the FCFF method which was determined to be overvalued compared to its intrinsic value. The research of Fayana and Jatmiko (2012) indicates that using the DDM method demonstrates that stock market prices are overvalued compared to the intrinsic price of stocks and the valuation of intrinsic value of LQ45 stocks in certain banks (BNI, Danamon and Mandiri) using a PBV method which uncovered an undervalued price. Wahyudi and Surya (2013) studied the valuation of PT Dayamitra's stock value on IPO plan using FCFE and PER methods. That research determines that the intrinsic value of the company ranged from IDR 15,000 to IDR 20,000. From the perspective of strategy, finance and the valuation of the stock, it was recommended that the company postpone the IPO plan to ensure a better value.

Winoto (2013) examines the valuation of stock intrinsic value of PT Fajar Sakti Coal Mining Company using a FCFE method with the valuation results indicating that the company had a higher value compared to the previous assessment. The research conducted by Hasanah and Rusliati (2017) observes the valuation of stock intrinsic values of companies listed on LQ45 using DDM and PBV methods. The results of that research show that the stock intrinsic value produced by DDM was more accurate than those produced by PBV with the average Root Mean Squared Error (RSME) of DDM smaller than the average RSME of PBV. Research conducted by Neaxie and Hendrawan (2017) examines the valuation of the stock price of telecommunication companies listed on the IDX using the FCFF, relative PER, PBV and Multiple EBITDA methods. It was concluded that most of the stock prices were overvalued against their intrinsic values. Lastly, Nopriandy (2016) examines the valuation of stock intrinsic value of PT Semen Baturaja Tbk using FCFE and PER methods, concluding that the market price was undervalued against its stock intrinsic value.

The phenomenon of the stock price of the tower provider industry and the varied results of the empirical studies make the valuation of this industry important. This study aims to determine the stock 
intrinsic value of tower industry companies listed on the Indonesian Stock Exchange, compare to the market price.

\section{Literature Review}

\subsection{Discounted Cash Flow}

Cash Flow refers to the incoming and outgoing cash flow from company activities. The Discounted Cash Flow approach is the basic model underlying all company valuation calculations. This approach estimates the intrinsic value of an asset based on its fundamentals. Discounted Cash Flow is used to assess equity in a business, or a company as a whole, or even a small part of the company (Damodaran, 2012). The DCF approach is the most commonly used model because it forms the basis of other valuation models. It states that the value of an asset is the present value of cash flow expectations that will be generated in the future at a certain discount rate. A company should have a stable profit/cash flow so that the stability of income and growth of the company is more predictable. The DCF method consists of three types of valuation approaches: Dividend Discounted Model (DDM), Free Cash Flow to Equity (FCFE), and Free Cash Flow to the Firm (FCFF).

\subsection{Free Cash Flow to Firm}

FCFF is the position of cash flow to all stakeholders including stockholders, bondholders and preferred stock holders (Damodaran, 2012). The Value of the Firm is obtained from the present value of cash flows, assuming all equity financing plus the net present value of tax is made by using debt. The following is the FCFF formula:

\section{FCFF $=$ EBIT (1-tax) + Depreciation + Capex-Change of Working Capital}

After obtaining the FCFF, the Value of the Firm is calculated by discounting FCFF on WACC (Weighted Average Cost of Capital).

Value of Firm $=\sum_{t=1}^{t=n} \frac{C F \text { to Firm }}{t}$

WACC is a weighted average of Cost of Capital covering debt, equity and hybrid securities used by companies to fund their financial needs (Damodaran, 2012). The Cost of Capital is a cost that must be incurred by a company to obtain funds from debt, equity and hybrid securities to fund an investment or company operation. The Cost of Capital is calculated based on the cost for each funding source (individual). However, if the company uses several sources of funds, the calculated Cost of Capital is the weighted average cost of all capital used or WACC. WACC can be calculated as follows:

\section{WACC = Comp of equity*rate of equity+Comp of Debt*rate of debt $) *(1-$ tax $)$}

\subsection{Valuation Relative through the approach of Price Earning Ratio}

In the relative valuation method, the assets are assessed based on the asset price in the market. The relative valuation is widely used for several reasons. Firstly, an assessment based on variable comparison of a number of comparison companies can be completed with little assumption and is faster than a discounted cash flow (DCF) valuation. Secondly, relative valuations are simpler to understand and easier to present to clients and customers than DCF valuations. Next, PER is the market price of a stock divided by its EPS. This ratio calculates the company's ability to generate profits. The smaller the PER stock of a company, the better 
it will be to buy its stocks. This means that the company is better able to generate profits. In this approach, the PER of the company will be compared to the PER of other similar companies. If the company's PER value is low, it can be said that the company is undervalued and becomes an attractive investment choice. The following is the formula of PER:

\section{PER = Market Value of Equity}

\section{Equity Earnings}

\subsection{Valuation Relative through the approach of Price Book Value}

PBV ratio allows investors to compare the book value of a stock with its market value. The PBV ratio can provide information on how many times the market value of a stock has been valued from its book value. A high PBV of stocks compared to other stocks in the same industry indicates that the stock price is relatively expensive. Lower PBV value of a stock indicates that the stock is undervalued. Therefore, those stocks are a good long-term investment. The PBV formulas is as follows:

\section{PBV = Market Value of Equity}

\section{Book Value of Equity}

\section{Research Methodology}

This research used a verificative, descriptive and comparative methodology. Descriptive research is used to determine the value of a variable using existing data which is then analyzed (Sekaran \& Bogie, 2013). Verificative research aims to examine the proposed variables accompanied by previous empirical data (Sekaran \& Bogie, 2013). Comparative research compares a variable at different times (Sekaran \& Bogie, 2013). In this study, several methods will be compared to valuate stock prices and to compare the stock prices of valuation results to market prices.

The first thing to do is conduct a historical analysis of the company's financial performance in the period of 2014-2017. The analysis was conducted to examine the management of assets, liabilities and company equity. The overall analyses were conducted using a financial ratio analysis. Following this, projections of growth revenue, balance sheets and cash flow were obtained. The projections were performed to determine the present value of cash flow that was expected to occur in the future. Three scenarios involved in the projections were optimistic scenarios (above historical growth of the company), moderate scenarios (in accordance with the historical growth of the company), and pessimistic scenarios (below the historical growth of the company).

The next step in the research was to conduct the valuation using one of the DCF - FCFF methods within the three scenarios. The FCFF method shows the amount of cash flow to all stakeholders including stockholders, bondholders and preferred stock holders (Damodaran, 2012). The Value of the Firm is obtained from the present value of cash flows, assuming all equity financing plus the net present value of the tax is made using debt. Then, the valuation using the relative PER method in 3 scenarios was also conducted. The PER ratio assists stock analysts to focus on important variables by estimating earnings per stock and PER. Following this, a PBV relative method was used to determine the valuation in the 3 scenarios. The PBV ratio allows investors to compare the book value of a stock with its market value. PBV can provide information on how many times the market value of a stock has been valued from its book value. A high PBV of stocks compared to other stocks in the same industry indicates that the stock price is relatively expensive, whereas a lower PBV value of a stock indicates that the stock is undervalued. PBV is useful to determine long-term investments. Finally, after obtaining the valuation of the stock's intrinsic value using the DCF-FCFF method, 
the PER and PBV were compared to the market stock price to determine whether they are overvalued or undervalued.

\section{Results}

After all of the data was analyzed and processed, the results of the overall valuation using the DCF method and relative method are shown in the following description in the form of the intrinsic value of each company, which is also compared to the stock market value.

Table 4.1 Valuation Results

\begin{tabular}{|c|c|c|c|c|c|c|}
\hline Perusahaan & Metode & Pendekatan & Skenario & Harga Pasar & Harga Intrinsik & Assesment \\
\hline \multirow{9}{*}{ TBIG } & \multirow{3}{*}{ DCF } & \multirow{3}{*}{ FCFF } & Opt & \multirow{9}{*}{6,450} & 8,379 & Undervalued \\
\hline & & & Mod & & 6,556 & Undervalued \\
\hline & & & Pes & & 5,065 & Overvalued \\
\hline & \multirow{6}{*}{ Relative } & \multirow{3}{*}{ PER } & Opt & & 5,973 & Overvalued \\
\hline & & & Mod & & 5,616 & Overvalued \\
\hline & & & Pes & & 5,021 & Overvalued \\
\hline & & \multirow{3}{*}{ PBV } & Opt & & 15,392 & Undervalued \\
\hline & & & Mod & & 14,624 & Undervalued \\
\hline & & & Pes & & 13,658 & Undervalued \\
\hline \multirow{9}{*}{ TOWR } & \multirow{3}{*}{ DCF } & \multirow{3}{*}{ FCFF } & Opt & \multirow{9}{*}{3,950} & 3,389 & Overvalued \\
\hline & & & Mod & & 3,060 & Overvalued \\
\hline & & & Pes & & 2,751 & Overvalued \\
\hline & \multirow{6}{*}{ Relative } & \multirow{3}{*}{ PER } & Opt & & 2,188 & Overvalued \\
\hline & & & Mod & & 2,298 & Overvalued \\
\hline & & & Pes & & 2,310 & Overvalued \\
\hline & & \multirow{3}{*}{ PBV } & Opt & & 3,851 & Overvalued \\
\hline & & & Mod & & 4,224 & Undervalued \\
\hline & & & Pes & & 4,582 & Undervalued \\
\hline \multirow{9}{*}{ SUPR } & \multirow{3}{*}{ DCF } & \multirow{3}{*}{ FCFF } & Opt & \multirow{9}{*}{6,800} & 6,826 & Undervalued \\
\hline & & & Mod & & 6,819 & Undervalued \\
\hline & & & Pes & & 6,814 & Undervalued \\
\hline & \multirow{6}{*}{ Relative } & \multirow{3}{*}{ PER } & Opt & & 12,700 & Undervalued \\
\hline & & & Mod & & 13,920 & Undervalued \\
\hline & & & Pes & & 15,100 & Undervalued \\
\hline & & \multirow{3}{*}{ PBV } & Opt & & 2,587 & Overvalued \\
\hline & & & Mod & & 3,115 & Overvalued \\
\hline & & & Pes & & 3,741 & Overvalued \\
\hline \multirow{9}{*}{ IBST } & \multirow{3}{*}{ DCF } & \multirow{3}{*}{ FCFF } & Opt & \multirow{9}{*}{8,100} & 4,134 & Overvalued \\
\hline & & & Mod & & 3,059 & Overvalued \\
\hline & & & Pes & & 2,221 & Overvalued \\
\hline & \multirow{6}{*}{ Relative } & \multirow{3}{*}{ PER } & Opt & & 5,284 & Overvalued \\
\hline & & & Mod & & 4,611 & Overvalued \\
\hline & & & Pes & & 3,924 & Overvalued \\
\hline & & & Opt & & 2,092 & Overvalued \\
\hline & & PBV & Mod & & 1,890 & Overvalued \\
\hline & & & Pes & & 1,641 & Overvalued \\
\hline
\end{tabular}

Source : Data Processed (in IDR)

The price of the TBIG stocks, as of 1 January 2018, was IDR 6,450. When the price was compared to the intrinsic value using the DCF-FCFF method, in an optimistic scenario it became IDR 8,379 meaning it was 
undervalued. In a moderate scenario the price was undervalued at IDR 6,556 and in a pessimistic scenario it was overvalued at IDR 5,065.

Through the DCF-FCFF method, the price ranged between IDR 5,065 to IDR 8,379. Furthermore, investors who want to sell can start selling the TBIG stocks in the highest scenario of optimism at the price of IDR 8,379, while those who want to buy can bid the stock price in the lowest scenario of pessimism at IDR 5,065 . Meanwhile, the intrinsic value of the moderate scenario becomes the intersection for those who want to sell at the highest price and those who want to buy at the lowest price. Therefore, the market price should approach the price of the moderate scenario, because the moderate scenario is the most likely scenario. This study shows that the intrinsic value of TBIG stocks calculated using the DCF method of the FCFF approach in a moderate scenario of IDR 6,556 was the closest price to the market price of IDR 6,450. Furthermore, if the price of TBIG stocks as of 1 January 2018 of IDR 6,450 was compared to the intrinsic value using a relative method with a PER approach in all scenarios, the optimistic scenario price is IDR 5,973, the moderate price is IDR 5,616, and the pessimistic price is IDR 5,021; all of the results are therefore overvalued.

The intrinsic value using the PER approach was calculated by comparing the PER of TBIG to the average PER of all ITP companies to determine whether TBIG stock prices were cheap or expensive compared to similar industries. Meanwhile, if the stock price of TBIG as of 1 January 2018 was IDR 6,450, which was compared to the intrinsic value using the relative method of the PBV approach in all scenarios, the prices are undervalued. Through the PBV approach, the intrinsic value is also calculated based on the average PBV ratio of the same company in similar industries, so that the intrinsic price of the PBV approach will depend on its competitors and also on the industry. As most of the stock valuation results were undervalued, it can be concluded that the stock market prices were categorized to be the best price to buy. From an investment point of view, it is recommended that TBIG stocks be purchased as their market price is close to the intrinsic price of the stock.

The price of TOWR stock was IDR 3,950 at 1 January 2018. When compared with the intrinsic price using the DCF-FCFF method, the price in the optimistic, moderate, and pessimistic scenarios were IDR 3,389, IDR 3,060, and IDR 2,751 respectively, which are all categorized as overvalued. Through the DCFFCFF method, the price ranged from IDR 2,751 to IDR 3,389. Consequently, investors who want to sell that stock can start selling the TOWR stock in the optimistic scenario at IDR 3,389. On the other hand, those who want to buy can bid the stock price at the lowest price of IDR 2,751 in the pessimistic scenario. In fact, the intrinsic price of the moderate scenario is the intersection price between those who want to sell stocks at the highest price and those who want to buy stocks at the lowest price. Hence, the market price should approach the price of the moderate scenario, because the moderate scenario is the most likely scenario.

Furthermore, if the TOWR stock price as of 1 January 2018 was IDR 3,950, which was then compared to the intrinsic price using the relative approach of the PER method in all scenarios, the results show that in the optimistic scenario, the price was IDR 2,188, in moderate scenario, the price was IDR 2,289, and in pessimistic scenario, the price was IDR 2,310. All of these prices are overvalued. The intrinsic value using the PER approach was calculated by comparing the PER of TOWR with the average PER of all ITP companies to determine whether the TOWR stock price was cheap or expensive compared to similar industries. At the same time, if the TOWR stock was IDR 3,950 as of 1 January 2018, when it was compared to the intrinsic price using the relative method of the PBV approach, the price in the optimistic scenario is IDR 3,851 which is overvalued, while the price in the moderate and pessimistic scenarios is IDR 4,224 and IDR 4,582 respectively, which are undervalued.

In the PBV approach, the intrinsic value was also calculated based on the average PBV ratio of the same company in similar industries, so that the intrinsic price of the PBV approach will depend on the competitors and the industry. From the TOWR stock valuation analysis, the stock market price included the expensive stock price category as most of the stock valuation results were overvalued. According to this, it is better to sell TOWR stocks and it is not recommended to purchase those stocks. 
As of the 1 January 2018, the SUPR stock price was IDR 6,800 and when it is compared to the intrinsic price using the DCF-FCFF method, the prices are: optimistic scenario $=$ IDR 6,826 , moderate scenario $\mathrm{i}=$ IDR 6,819, and pessimism scenario = IDR 6,814. All of these prices are undervalued. Therefore, the stock prices through the DCF-FCFF method ranges from IDR 6,814 to IDR 6,826. As a consequence, investors who want to sell the stock can start selling SUPR stocks in the optimistic scenario at the price of IDR 6,826, whereas those who want to buy it can bid the stock price in the pessimistic scenario at IDR 6,814 . The intrinsic price of the moderate scenario is the intersection price between those who want to sell stocks at the highest price and those who want to buy stocks at the lowest price. Therefore, the market price should approach the price of the moderate scenario, because the moderate scenario is the most likely scenario. If the SUPR stock price as of 1 January 2018 was IDR 6,800, the prices in all scenarios were undervalued compared to the intrinsic price using the relative method of the PER approach. The intrinsic value using the PER approach was calculated by comparing the PER of SUPR with the average PER of all ITP companies to determine whether the SUPR stock price was cheap or expensive compared to similar industries. Meanwhile, if the SUPR stock on 1 January 2018 was IDR 6,800 which was compared to the intrinsic price using the relative method of the PBV approach in all scenarios, the prices are: optimistic scenario = IDR 2,587, moderate scenario $=$ IDR 3,115 and pessimistic scenario $=$ IDR 3,741, which are all overvalued. By using the PBV approach, the intrinsic value was also calculated based on the average PBV ratio of the same company in similar industries. Therefore, the intrinsic price of the PBV approach will depend on competitors and the industry. As most of the stock valuation results were undervalued, the current stock market price is considered to be the best price. Therefore, TBIG stocks should be purchased because the stock market price is close to the intrinsic price of the stock.

With respect to IBST stocks, the IBST stock price as of 1 January 2018 was IDR 8,100. When it was compared to the intrinsic price using the DCF-FCFF method, the prices in the optimistic, moderate, and pessimistic scenarios were IDR 4,134, IDR 3,059, and IDR 2,221 respectively, which are all overvalued. Through the DCF-FCFF method, the price ranges between IDR 2,221 and IDR 4,134. Hence, investors who want to sell the stock can start selling IBST stocks in the optimistic scenario at IDR 4,134. Meanwhile, those who want to purchase the stock can bid the stock price at the pessimistic scenario at IDR 2,221. The intrinsic price of the moderate scenario is the intersection price between those who want to sell stocks at the highest price and those who want to buy stocks. Consequently, the market price should approach the price of the moderate scenario, because the moderate scenario is the most likely scenario. Furthermore, if the IBST stock price as of 1 January 2018 was IDR 8,100 compared to the fair price using the relative method of the PER approach in all scenarios, the optimistic scenario shows a price of IDR 5,284, the moderate scenario shows a price of IDR 4,611, and the pessimistic scenario shows a price of IDR 3,924. All of these prices are overvalued.

The intrinsic value using the PER approach was calculated by comparing the PER of SUPR with the average PER of all ITP companies to determine whether the SUPR stock price is cheap or expensive compared to similar industries. Meanwhile, if the IBST stocks as of 1 January 2018 was IDR 8,100 and was compared to the intrinsic price using the relative method of the PBV approach in all scenarios, the resulting prices were overvalued with IDR 2,092 in the optimistic scenario, IDR 1,890 in the moderate scenario, and IDR 1,641 in the pessimistic scenario. Using the PBV approach, the intrinsic value was also calculated based on the average PBV ratio of the same company in similar industries. Therefore, the intrinsic price of the PBV approach will depend on competitors and the industry. As a result, the stock market price is currently very expensive as most of the stock valuation results were overvalued. Consequently, it is better to sell IBST stocks and it is not recommended to purchase the stocks.

\section{Discussion}

The final results of the stock valuation analyses of the tower providers using the Discounted Cash Flow method of the Free Cash Flow to Firm approach, and the Relative method of the PER and PBV approaches 
are described as follows. Most of the TBIG and SUPR stock valuations show that their stock market prices were undervalued against the intrinsic price of the stock, which means that the stock prices are good prices in the current market. TBIG and SUPR need only to maintain or even improve their performance so that many of their stocks will attract investors. On the other hand, the valuation results of TOWR and IBST indicate that their stock market prices are overvalued against their intrinsic prices, so that they are classified as expensive. For this reason, TOWR and IBST should split their stocks to improve their market stock prices. By splitting their stock, in addition to obtaining stock prices that are close to their intrinsic prices, they will also obtain fresh funds that can be used to improve company performance.

From an investor's point of view, the stock valuation results show that TBIG and SUPR stocks are good stocks to purchase because their stock market prices are similar to the intrinsic price of the stock or even below it. This also provides investors with an opportunity to make a profit. With respect to TOWR and IBST stocks, as their valuations show that their stock market prices are overvalued against their intrinsic price, they are classified as expensive stocks, and investors should refrain from buying those stocks until their intrinsic price improves.

\section{Conclusion}

In accordance with the stock market prices as of 1 January 2018, this study concludes that when stock prices are compared to the intrinsic value of the stock valuation of the DCF-FCFF method in an optimistic scenario, TBIG and SUPR are undervalued, while TOWR and IBST are overvalued. In a moderate scenario, TBIG and SUPR are undervalued, while TOWR and IBST are overvalued. In a pessimistic scenario, TBIG, TOWR and IBST are overvalued, whereas only SUPR is undervalued. At the same time, a relative valuation using the PER approach in all scenarios show that TBIG, TOWR and IBST are overvalued and SUPR is undervalued. A relative valuation of the PBV approach in all scenarios determines that TOWR, SUPR and IBST are overvalued, and only TBIG is undervalued. This research also suggests that TOWR and IBST should split their stocks to improve their market stock prices. According to the results, this study provides information for investors that TBIG and SUPR stocks are good stocks to purchase. In contrast, investors should refrain from buying TOWR and IBST stocks until both stocks are split.

Last but not least, the valuation of this research produces an intrinsic value with the DCF method that is closer to the market price than the relative method. The intrinsic value of TBIG stocks using the DCF method ranges from IDR 5,065 to IDR 8,379, while the relative method ranges from IDR 5,021 to IDR 15,392. The TOWR stock price using the DCF method ranges from IDR 2,751 to IDR 3,389, while the relative method ranges from IDR 2,188 to IDR 4,582. Further, the stock price of SUPR using the DCF method ranges from IDR 6,814 to IDR 6,826, while the relative method ranges from IDR 2,587 to IDR 15,100. Lastly, the stock price of IBST using the DCF method ranges from IDR 2,221 to IDR 4,134, while the relative method ranges from IDR 1,641 to IDR 5,584.

Future research should include other valuation methods, such as contingent claims for the valuation of company stocks.

\section{References}

Barth, B. E., Beaver, W. H. and Landsman, W. R. (1998). Relative Valuation Roles of Equity Book Values and Net Income as a Function of Financial Health. Journal of Accounting and Economics, 25, 1-34.

Benaji, R. M. 2011. Valuation on the intrinsic value of perum pegadaian stocks using the method of free cash flow to equity. (Thesis not publised). Jakarta : Indonesian University.

Charumathi \& Suraj, 2014, The Reability Of Dividend Discount Model In Valuation Of Bank Stocks At The Bombay Stock Exchange. International Journal of Accounting and Taxation 2:2, 111-127

Damodaran, A. (2012). Investment valuation: Tools and techniques for determining the value of any asset (Vol. 666). John Wiley \& Sons. 
Fayana, Ermia \& Jatmiko, Singgih. 2012.Valuation on the intrinsic value using the method of DDM and PBV on banking sector which include LQ45 stocks in Indonesian Stock Exchange. Gunadarma University Jakarta

Graham, J. R. 2001. Estimating the Tax Benefits of Debt. Journal of Applied Corporate Finance, 43-54.

Gilbert, G.A.1990. Discounted Cash Flow Approach to Valuation. CFA Publication. 23 - 30

Gumanti, T.A. (2011). Investment Management Concepts, Theory and Application. Jakarta : Mitra Wacana Media Hasanah, R. S. \& Rusliati, Ellen. 2017. Valuation of stock intrinsic value of companies listed on LQ45 using DDM and PBV method. Journal of Business and Management Research (JRBM). 10:2., 1-10. Pasundan University Bandung

Hutapea, E. C., Putri, T. P.P. \& Sihombing, P. 2012. Valuation of stock intrinsic value Adaro Energy Company using FCFF method. Al Azhar University Jakarta

Imbarine, B. 2017. The relevance of Gordons model and Earnungs multiplier approach in emerging stock market : Test with appropriate refinements. International Research Journal of Finance and Economics, ISSN 1450-2887 Issue 7

Inselbag, I., \& Kaufold, H. 1997. Two DCF Approaches for Valuing Companies Under Alternative Financing Strategies (And How to Choose Between Them ). Journal of Applied Corporate Finance, 114-122.

Ivanovska, N., Zoran I., \&Zoran, Narasanov. 2014. Fundamental analysis and discounted free cash flow valuation of stock at mse. UTMS Journal of Economics.5:1, 11-24

Kasim, Y. Y. 2011. Valuation of stock intrinsic value Garuda Indonesia using PV of EBITDAR and Hidden value method. (Thesis not publised). Jakarta: Indonesian University

Neaxie, Lidya. Vega. \& Hendrawan, Riko. 2017. Share valuation using DCF and Relative method of telecommunication company listed in Indonesian stock exchange for forecast period 2017. Telkom University

Nel, W.S. 2009. Methods of choice of in valuation of ordinary shareholders equity: evidence from theory and practice. Meditary Accountancy Research, 17:2, 117 -135. Departemen of Accounting University of Sttelenbosch Nopriandy, Fajar. 2016. Valuation of stock intrinsic value Semen Baturaja Company using FCFE Method. (Thesis not publised). Lampung : Lampung University

Olweny,Tobias, 2011, The Reliability of Dividend Discount Model in Valuation of Common Stock at the Nairobi Stock Exchange. International Journal of Business and social science

Prasar, S. \& Anggarwal, R.K. (2009). The intellectual property valuation - A case of Jet Airways, the innovative and critical times ahead, an Indian perspective. Journal of Wolrd Academy of Science, Engineering and Technology, 53, $1264-1270$.

Santos,D.2017. Adidas Group Equity Valuation.(Thesis not publised).Lisbon:Univ Catolica Portuguesa Simorangkir, J. P. S. 2012 Valuation of stock intrinsic value BNI Company using DEA and PBV. Perbanas Steiger, Florian. 2009. The Validity of Company Valuation using Discounted Cash Flow Methods Seminar Paper Fall

Wahyudi, A ., \& Surya, B. A. 2013. Company valuation analysis on Daya mitra Telecommunication in preparation on IPO. The Indonesian Journal Of Business Administration. Vol. 2, No. 4. Institute of Technology Bandung

Winoto, W. E. 2013. Valuation of stock intrinsic value Fajar Sakti company. (Thesis not publised). Yogyakarya: Universitas Gajah Mada 